CZASOPISMO INŻYNIERII LĄDOWEJ, ŚRODOWISKA I ARCHITEKTURY JOURNAL OF CIVIL ENGINEERING, ENVIRONMENT AND ARCHITECTURE JCEEA, t. XXXIII, z. 63 (4/16), październik-grudzień 2016, s. 9-16

\author{
Jerzy BAKALARCZYK ${ }^{1}$
}

\title{
UKŁADY ŁADOWANIA BATERII W NOWOCZESNYCH SYSTEMACH FOTOWOLTAICZNYCH
}

\begin{abstract}
Układy ładowania akumulatorów odgrywają ważną rolę w systemach fotowoltaicznych. Od nich zależy bezpieczna praca całego zespołu. Stanowią one element pośredniczący między panelami fotowoltaicznymi a pozostałą częścią systemu. Zawierają one obwody zwane popularnie kontrolerami ładowania. Kontrolery ładowania baterii akumulatorów zapewniają im wymaganą żywotność i zabezpieczają te urządzenia przed przeładowaniem oraz całkowitym rozładowaniem oraz zapewniają właściwy przebieg cyklu ładowania. W pracy tej przedstawiono dwa typy akumulatorów stosowanych obecnie w systemach fotowoltaicznych oraz podano ich krótką charakterystykę. W obecnym czasie zwraca się szczególną uwagę na ochronę środowiska naturalnego. Zagadnienie dotyczy również fotowoltaiki. Wskazano na możliwość szerszego wykorzystania akumulatorów niklowo - żelazowych Ni-Fe, których stosowanie nie jest jeszcze tak popularne w tych systemach, ale posiadają one wiele pozytywnych cech, jak ponad 20 letnia żywotność oraz odporność na trudne warunki eksploatacyjne i są one bardziej bezpieczne dla środowiska niż - kwasowo - ołowiowe. Różne typy akumulatorów wymagają różnych metod ładowania i różnych warunków eksploatacyjnych, co należy uwzględnić przy stosowaniu kontrolerów ładowania. Z uwagi na dużą różnorodność systemów fotowoltaicznych stosuje się w nich różne kontrolery ładowania różniących się budową wewnętrzną i zasadą pracy. Dokonano również klasyfikacji tych układów oraz przedstawiono najważniejsze topologie układów ładowania. Przedstawiono wersję symulowanego układu ładowania i wyniki badań. Artykuł zakończono wnioskami nasuwającymi się podczas realizacji tej pracy.
\end{abstract}

Słowa kluczowe: akumulatory niklowo - żelazowe Ni-Fe, typ akumulatora, falowniki, kontrolery ładowania, topologie kontrolerów

\section{Wprowadzenie}

$\mathrm{Z}$ uwagi na rosnące zapotrzebowanie energetyczne zainteresowanie fotowoltaiką również wzrasta. Potrzebne są urządzenia charakteryzujące się wysoką sprawnością, niezawodnością oraz - rozwiązania przyjazne dla środowiska.

\footnotetext{
1 Jerzy Bakalarczyk, Wyższa Szkoła Gospodarki, Instytut Informatyki i Mechatroniki, ul. Garbary 2, 85-229 Bydgoszcz; tel. 503363281; jbakal1@wp.pl
} 
W systemach tych wyposażonych w akumulatory należy zwrócić uwagę na zastosowanie właściwych układów ładowania.

\section{System fotowoltaiczny}

Podstawowy schemat blokowy systemu fotowoltaicznego, zawierającego akumulatory, został przedstawiony na Rys.1. Zawiera on panele fotowoltaiczne, blok ładowania akumulatorów, przekształtnik oraz obciążenie. Panele służą do

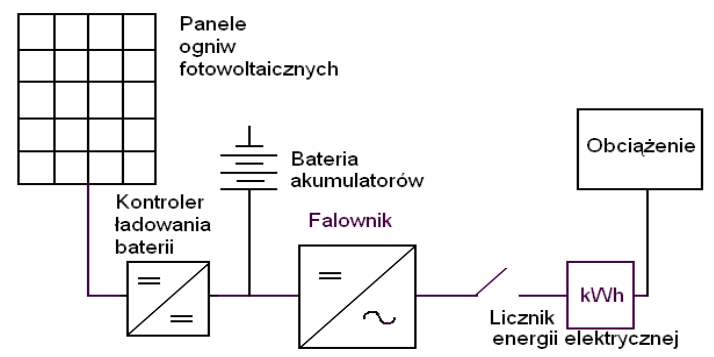

Rys.1. Podstawowy schemat blokowy systemu fotowoltaicznego

Fig.1. A basic block scheme of photovoltaic system

przekształcania energii słonecznej na energię elektryczną, która doprowadzana jest do akumulatorów poprzez obwody ładowania zawierające kontrolery ładowania baterii oraz - falowniki zamieniających napięcie stałe $\mathrm{z}$ akumulatorów na napięcie przemienne. Kontrolery ładowania posiadają różne wykonania w zależności od wymagań użytkowników ceny oraz rodzaju zastosowanych akumulatorów.

\section{Układy ładowania baterii akumulatorów}

Układy ładowania baterii w systemach fotowoltaicznych złożone są z trzech podstawowych obwodów: paneli fotowoltaicznych jako źródeł napięcia zmieniającego parametry w zależności od natężenia promieniowania słonecznego - baterii akumulatorów oraz - kontrolerów ładowania baterii akumulatorów (Rys.1). W układach ładowania głównie występują różnice w topologii kontrolerów ładowania (Rys.2, a - f).

Panele fotowoltaiczne zostały szeroko opisane w literaturze [7], [8]. Z uwagi na szeroki dostęp informacji na ich temat, nie zostały one tu uwzględnione.

\subsection{Akumulatory}

Akumulatory stanowią jeden z elementów układu ładowania w systemie fotowoltaicznym. Porównanie akumulatorów ołowiowo - kwasowych i niklowo żelazowych stosowanych w układach fotowoltaicznych przedstawiono w Tabe- 
li 1. Na szczególną uwagę zasługują akumulatory niklowo-żelazowe Ni-Fe. Akumulatory te charakteryzują się odpornością na szerokie zmiany temperatury, - dużą pojemnością oraz - odpornością na zwarcia i przeładowania. Są bardziej przyjazne dla środowiska niż - ołowiowo- kwasowe. W akumulatorze Ni-Fe ujemną elektrodę stanowi żelazo a dodatnią - wodorotlenek niklu natomiast elektrolitem jest $21 \%$ (wagowo) roztwór wodorotlenku potasu $\mathrm{KOH} \mathrm{z} \mathrm{małym}$ dodatkiem soli litu. Siła elektromotoryczna takiego akumulatora wynosi 1,4 -1,2 V. W 2005 r. zostały przeprowadzone badania laboratoryjne na prototypie akumulatora szczelnego niklowo - żelazowego Ni-Fe [1], które zakończyły się wynikiem pomyślnym.

Niektóre akumulatory stosowane także w systemach fotowoltaicznych to:

- szczelne ołowiowo-kwasowe (ang. Seald Lead - Acid),

- litowo - jonowe Li-Ion,

- litowo - polimerowe Li-Poly,

- ogniwa niklowo-wodorkowe Ni-MH.

Istnieje również możliwość stosowania akumulatorów sodowo - siarkowych NaS. Głównym problemem jest tu utrzymanie temperatury pracy na poziomie ok. $350^{\circ} \mathrm{C}$ oraz - wysokiego stopnia szczelności. Podczas awarii może dojść do wybuchu i pożaru. Są one bez przerwy udoskonalane.

\subsection{Kontrolery ladowania akumulatorów}

Kontrolery ładowania stanowią zasadniczą część układów ładowania oraz zapewniają bezpieczną pracę akumulatorów i stanowią pośredniczący stopień pomiędzy panelami fotowoltaicznymi a baterią akumulatorów. Umożliwiają ładowanie akumulatorów, kontrolę stanu naładowania, chronią przed przeładowaniem, a czasami umożliwiają kompensację temperaturową. Metody ich sterowania opisuje szeroko literatura [6].

W pracy tej dokonano podziału istniejących topologii układów kontrolerów ładowania na dwa podstawowe rodzaje:

- O działaniu ciągłym (niska sprawność):

- w układzie równoległym (obniżanie napięcia) - Rys.2a,

- w układzie szeregowym (obniżanie napięcia) - Rys.2.b.

- O działaniu impulsowym (wysoka sprawność):

- w układzie szeregowo - równoległym (zarówno obniżanie i podwyższanie napięcia) - Rys.2.c,

- w układzie szeregowym (obniżanie napięcia) - Rys.2.d,

- w układzie równoległym (podwyższanie napięcia) - Rys.2.e.

Wykorzystują one różne strategie sterowania [2], [4], [6], umożliwiając efektywne ładowanie akumulatorów oraz wykorzystanie energii elektrycznej $\mathrm{z}$ paneli fotowoltaicznych. 
Tabela 1. Porównanie akumulatorów ołowiowo - kwasowych i niklowo - żelazowych

Table 1. Comparison of Lead -Acid and Nikel - Iron batteries

\begin{tabular}{|c|c|}
\hline \multicolumn{2}{|c|}{ Akumulatory ołowiowo - kwasowe i niklowo - żelazowe } \\
\hline $\begin{array}{l}\text { Akumulatory ołowiowo- kwasowe z cie- } \\
\text { kłym elektrolitem w postaci wodnego roz- } \\
\text { tworu kwasu siarkowego }\end{array}$ & $\begin{array}{l}\text { Są tanie. Ich wadą jest duża masa, konieczność uzu- } \\
\text { pełniania elektrolitu. Gazowanie podczas ostatniej } \\
\text { fazy ładowania. Użytkowane muszą być w pomiesz- } \\
\text { czeniach dobrze przewietrzanych. Zawierają ołów. } \\
\text { Wydzielają się szkodliwe dla otoczenia opary kwasu } \\
\text { siarkowego. Czas życia - około } 10 \text { lat. }\end{array}$ \\
\hline Akumulatory niklowo-żelazowe Ni-Fe & $\begin{array}{l}\text { Są dużo trwalsze od ołowiowo-kwasowych, są od- } \\
\text { porne na przeładowanie i nadmierne rozładowanie } \\
\text { i zwarcia. Idealnie nadają się do systemów fotowolta- } \\
\text { icznych. Występuje zjawisko gazowania podczas ich } \\
\text { ładowania i wrasta ono wraz ze wzrostem prądu } \\
\text { ładowania (należy zapewnić przewietrzanie). Pod- } \\
\text { czas tadowania należy zapewnić napięcie 1,46 do } \\
\text { 1,55V na ogniwo i uzupełniać elektrolit. Czas życia } \\
\text { 30-40 lat. }\end{array}$ \\
\hline
\end{tabular}

Na Rys.2, a,b,c,d,e przedstawiono podstawowe topologie kontrolerów ładowania baterii akumulatorów wykorzystywanych w systemach fotowoltaicznych.
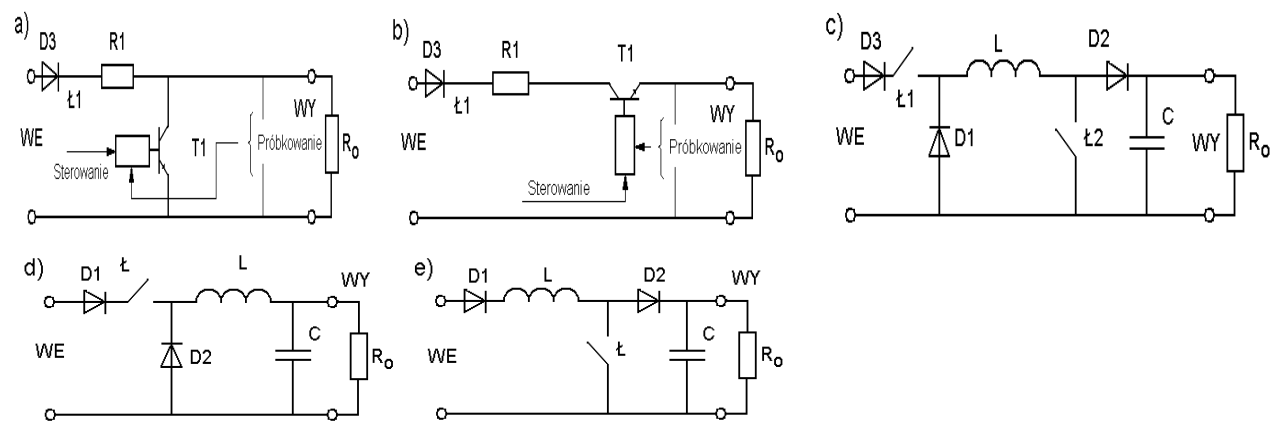

Rys.2. Topologie kontrolerów ładowania w systemach fotowaoltaicznych: równoległy o działaniu ciągłym: a) szeregowy o działaniu ciągłym; b) obniżająco - podwyższający o działaniu impulsowym; c) obniżający o działaniu impulsowym; d) podwyższający o działaniu impulsowym; e) $\mathrm{R}_{0}$ - obciążenie kontrolera (akumulator); WE - napięcie wejściowe z paneli fotowoltaicznych

Fig.2. Topologies of charger controllers used in Photovoltaic Systems: Parallel continuous charger: a) serial continuous charger; b) buck - boost battery charger for on - off operation; c) buck battery charger for on-off operation; d) boost battery charger for on-off operation; e) $\mathrm{R}_{0}$ - charger load (battery); WE -input voltage from photovoltaic panels 


\section{Opis procedury badawczej}

Zastosowano badania symulacyjne tworzonego nowego rozwiązania konstrukcyjnego układu ładowania akumulatorów, w oparciu o program symulacyjny PSpice.

\section{Metodyka i wyniki badań}

Przeprowadzono badania symulacyjne, $\mathrm{z}$ wykorzystaniem programu PSpice, opracowanego układu o topologii układu dwustopniowego obniżająco podwyższającego kontrolera ładowania baterii z Rys.3.

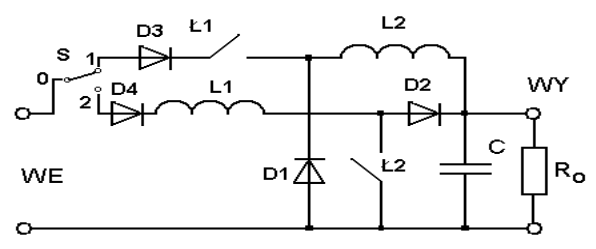

Rys.3. Topologia zasymulowanego kontrolera impulsowego dwustopniowego obniżająco podwyższającego

Fig.3. Topology of simulated of two - stage buck - boost battery charger for on-off operation

Schemat układu symulacyjnego przedstawiono na Rys.4. Do wejścia układu „WE" doprowadzane jest napięcie z paneli fotowoltaicznych. Wyjście układu „WY" połączone jest z baterią akumulatorów. Praca układu jest dwustopniowa ustalana przełącznikiem ,S”. W położeniu „," przełącznika „S” układ znajduje się w trybie podwyższania napięcia wejściowego. W położeniu „2” przełącznika „S” układ znajduje się w trybie obniżania napięcia wejściowego.

Zarówno obwody podwyższania jak i obniżania pracują impulsowo. Przełącznik ,S” może być sterowany z mikrokontrolera lub obwodów FPGA. Łączniki Ł1 i Ł2 mogą być zasilane sygnałem prostokątnym z zewnętrznego generatora lub mikrokontrolera o częstotliwości $20 \mathrm{kHz}$. W torach obniżania i podwyższania napięcia zastosowano odrębne indukcyjności L1 i L2.

$\mathrm{W}$ miejsce akumulatora zastosowano obciążenie rezystancyjne R2 $=20 \mathrm{om}$. Napięcie z panelu fotowoltaicznego to ogniwo V1 $=24 \mathrm{~V}$. Na podstawie danych zebranych w Tabeli 1, przewidziano zastosowanie akumulatora niklowo - żelazowego Ni-Fe, który spełnia wymogi niezawodności i żywotności oraz odporności na trudne warunki pracy. Rys.7.

Wyniki przedstawiono w postaci przebiegów i podano na Rys.5, Rys.6, 


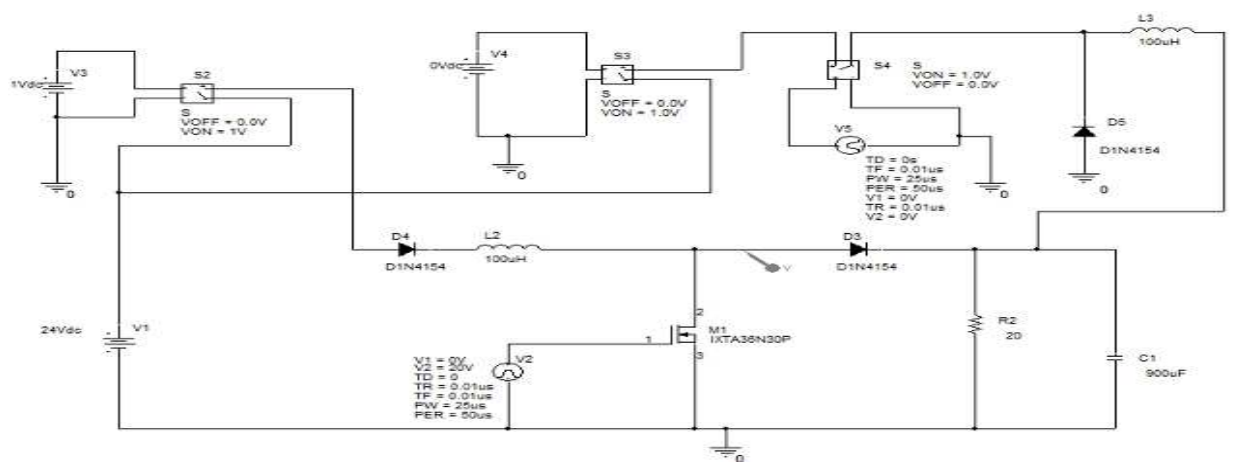

Rys.4. Schemat symulacyjny w programie PSpice zaproponowanego dwustopniowego kontrolera ładowania obniżająco - podwyższającego (patrz Rys.3)

Fig.4. PSpice simulation proposed scheme of two stages buck - boost battery charger (see Fig.3)
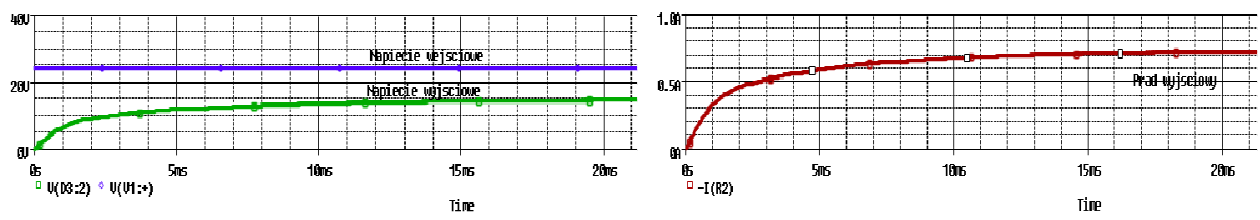

Rys.5. Przebiegi napięcia wejściowego i wyjściowego w zaproponowanym układzie kontrolera ładowania przy pracy w trybie obniżania napięcia (po lewej) oraz przebieg prądu wyjściowego tego układu (po prawej)

Fig.5. Input and output voltages (left) and output current (right) waveforms in proposed charging controller in buck - mode
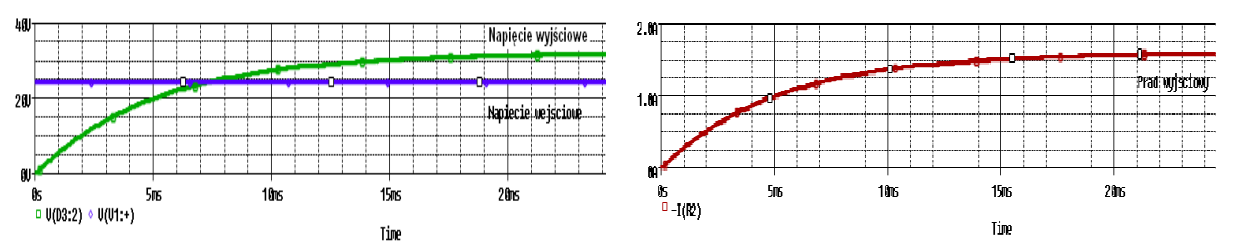

Rys.6. Przebiegi napięcia wejściowego i wyjściowego (po lewej) oraz przebieg prądu wyjściowego (po prawej) w zaproponowanym układzie kontrolera ładowania pracującego w trybie podwyższania napięcia

Fig.6. Input and output voltages (left) and output current (right) waveforms in proposed boost mode of battery charger system

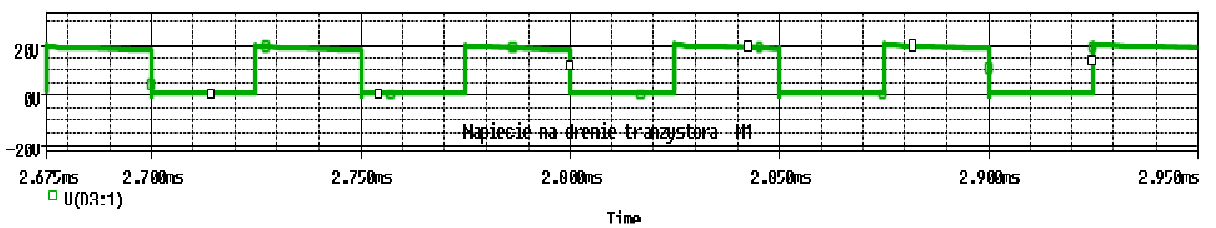

Rys.7. Przebieg napięcia na drenie tranzystora kluczującego M1 (patrz Rys.4)

Fig.7. Voltage waveform of M1 key trasistor drain (see Fig.4) 


\section{Analiza wyników}

Na podstawie uzyskanych przebiegów przedstawionych na Rys.5, Rys.6, oraz Rys.7. można stwierdzić, że przedstawiony dwustanowy (możliwość wyboru stanu pracy łącznikiem $S$ ) regulator ładowania baterii o topologii z Rys.3 może zostać zastosowany do ładowania baterii akumulatorów fotowoltaicznych. Może on reagować na zmiany wartości napięcia $\mathrm{z}$ paneli fotowoltaicznych. Umożliwia pracę zarówno w trybie obniżania wartości napięcia na zaciskach wyjściowych podłączonych do zacisków baterii jak jego podwyższania, w stosunku do napięcia wejściowego z paneli fotowoltaicznych. Możliwa jest zatem praca ze śledzeniem punktu mocy maksymalnej MPPT (ang. Maximum Power Point Tracking) [2]. Na Rys.6 przestawiony przebieg napięcia na drenie tranzystora kluczującego pracującego ze stałą częstotliwością $20 \mathrm{kHz}$.

\section{Wnioski}

Rozwój urządzeń w układach fotowoltaicznych idzie w kierunku poprawy ich sprawności jak i niezawodności i przedłużeniu czasu życia. Zastosowanie akumulatorów niklowo-żelazowych Ni-Fe daje możliwość spełnienia tego warunku oraz umożliwia tworzenie układów przyjaznych dla środowiska.

Zaproponowane rozwiązanie topologiczne dwustanowego kontrolera ładowania akumulatorów umożliwia zarówno sterowanie $\mathrm{z}$ modulacją szerokości impulsów PWM [6] jak i śledzenie punktu maksymalnej mocy MPPT [2] oraz daje możliwość dokonywania odrębnych nastaw (łącznik S) indukcyjności w torach obniżania i podwyższania napięć w kontrolerze ładowania. Rozwiązanie to umożliwia sterowanie $\mathrm{z}$ wykorzystaniem mikrokontrolera lub układu FPGA [3] oraz może być zastosowane w układach ładowania baterii w systemach fotowoltaicznych.

\section{Literatura}

[1] Hariprakash B., Martha S.K., Hegde M.S., Shukla A.K.: A sealed, starved-electrolyte nickel-iron battery, Journal of Applied Electrochemistry, Springer, January 2005, Volume 35, Issue 1, pp. 27-32.

[2] De Oliveira J.H., Carlette L.P., Cupertino A.F., Mendes V.F., Boaventura W.d.C., Pereira H.A.: Comparison of MPPT strategies in battery charging of photovoltaic systems, 2015 IEEE 24th International Symposium on Industrial Electronics (ISIE), Buzios, 2015, pp. 1242-1247.

[3] AbduAllah Z.M., Mahmood O.T., AL-Naib A.M.T.I.: Photovoltaic Battery Charging System Based on PIC16F877A Microcontroller, International Journal of Engineering and Advanced Technology (IJEAT), India, ISSN: 2249 - 8958, Volume-3, Issue-4, April 2014, pp. 27-31. 
[4] Shweta A.R., Kolte M.T., Hon S.P: A solar - powered battery charging system using Levenberg-Marquard algorithum, International Journal of Scientific \& Technology Research, Volume 2, Issue 9, September 2013, ISSN 2277-8616, pp. 59-61.

[5] Kamala J., Janarthanan V., Santhosh K.: Power Mosfet based photo-voltaic battery charger analysis and implementation, International Journal of Circuits, ISSN: 19984464, Systems and Signal Processing, Volume 9, 2015, pp. 33-39.

[6] Shoaib M., Nagaraj V.: Novel Battery Charging Control System for Batteries Using On/Off and PWM Controllers for Stand Alone Power Systems, IOSR Journal of Electrical and Electronics Engineering (IOSR-JEEE), India, e-ISSN: 2278-1676, ISSN: 2320-3331, Volume 6, Issue 3 (May - Jun. 2013), pp. 44-52.

[7] Tiwari G.N., Swapnil Dubey S.: Fundamentals of Photovoltaic Modules and Their Applications, 2010, Springer.

[8] Kalogirou S.: Solar Energy Engineering: Processes and Systems, Academy Press, 2014.

\section{BATTERY CHARGING CIRCUITS IN MODERN PHOTOVOLTAIC SYSTEMS}

\section{S u m m a r y}

The charging circuit of the batteries plays an important role in the photovoltaic systems. Safe operation of the entire system depends on the circuits. They are intermediary parts between the photovoltaic panels and the rest of the PV systems. They consists circuits which are popularly called the Solar Charge Controllers. Charge Controllers provide batteries with the required life and they protects batteries from overload and complete discharging and ensures them the proper charging cycles. One has presented two battery types for photovoltaic systems, and gave theirs brief description. At the present time one pays particular attention to ensuring the environmental protection. The problem also applies to the photovoltaics. One pointed to the possibility of wider use of nickel - iron $\mathrm{Ni}-\mathrm{Fe}$ batteries as the use of them is not popular in these systems yet, but they have many positive attributes such as more than 20 year life and robustness to difficult operating conditions and they are safer for the natural environment than - acid - lead ones. NiFe batteries have many positive features over lead - acid batteries. Different types of the batteries require different charging methods and different operating conditions which must be taken into account when applying the charging controllers. In view of the wide variety of Photovoltaic Systems, the charging controllers may differ each other in terms of internal structure and the principle of operation. One also has done classification of such circuits and presented the most important theirs topologies. Simulated version of the charging circuit and test results has been presented. The article has been completed with conclusions raised during realisation of this work.

Keywords: NiFe nickel iron batteries, battery type, the inverters, charge controllers, the controllers topologies

DOI:10.7862/rb.2016.243

Przestano do redakcji: $30.06 .2016 r$.

Przyjęto do druku: 20.12.2016 r. 